\title{
Capoeira: diálogo de saberes como possibilidade de valorização da (s) identidade (s) afro-brasileira (s) e do patrimônio imaterial
}

\author{
Capoeira: diálogo de saber como posibilidad de valorización de la (s) \\ identidad (s) afro-brasileña (s) y del patrimonio inmaterial
}

\author{
Capoeira: dialogue of knowledges as a possibility of valorization of Afro- \\ Brazilian identity (s) and intangible heritage
}

\section{Marcelo Pertussatti ${ }^{1}$}

\begin{abstract}
Resumo
A presente reflexão tem o objetivo de apresentar a relevância da Capoeira como possibilidade de diálogo de saberes nas discussões contemporâneas em torno dos processos decoloniais, a partir do reconhecimento de seu caráter ancestral, intercultural e patrimonial imaterial, bem como de sua identidade libertária e de resistência. Bastante expressiva desde o período Colonial brasileiro, fortemente criminalizada e discriminada durante a Primeira República, atualmente a Capoeira está presente em mais de 160 países e em todos os continentes, desde sua internacionalização na década de 60 do século passado. A análise de documentos brasileiros como o Dossiê de Registro e Salvaguarda da Capoeira como Patrimônio Cultural do Brasil e o Estatuto da Igualdade Racial busca contribuir, primeiramente, para o fortalecimento da Capoeira, de seus saberes em encontro e de suas expressões, bens culturais legítimos, isto é, para a afirmação identitária africana do povo brasileiro, mas também de cada praticante de Capoeira. A organização dialógica dos saberes da capoeira, por meio das perspectivas de sua corporeidade, musicalidade, simbologia, história e historicidade, ritualidade e ancestralidade, contribui para o cuidado patrimonial, para a formação da identidade cultural afro-brasileira.
\end{abstract}

Palavras-Chave: Capoeira; Identidade; Saberes; Patrimônio Imaterial; Perspectivas.

\section{Resumen}

La presente reflexión tiene el objetivo de presentar la relevancia de la Capoeira como posibilidad de diálogo de saberes en las discusiones contemporáneas en torno a los procesos de decolonización, a partir del reconocimiento de su carácter ancestral, intercultural y patrimonial inmaterial, así como de su identidad libertaria y de resistencia. Bastante expresiva desde el período colonial brasileño, fuertemente criminalizada y discriminada durante la Primera República, actualmente la Capoeira está presente en más de 160 países y en todos los continentes, desde su internacionalización en la década del 60 del siglo passado. El análisis de documentos brasileños como el Dossiê de Registro e Salvaguarda da Capoeira como Patrimônio Cultural do Brasil (Dossier de Registro y Salvaguarda de la Capoeira como Patrimonio Cultural de Brasil) y el Estatuto da Igualdade Racial (Estatuto de la Igualdad Racial) busca contribuir, primeramente, al fortalecimiento de la Capoeira, de sus saberes en encuentro y de sus expresiones, bienes culturales legítimos, es decir, para la afirmación identitaria aficanao del pueblo brasileño, pero también de cada practicante de Capoeira. La organización dialógica de los saberes de la capoeira, por medio de las perspectivas de su corporeidad, musicalidad, simbología, historia e historicidad, ritualidad y ancestralidad, contribuye al cuidado patrimonial, para la formación de la identidad cultural afro-brasileña.

Palabras claves: Capoeira; Identidad; Saberes; Patrimonio Inmaterial; Perspectivas.

\footnotetext{
1 Mestrando em Educação; Universidade Federal da Fronteira Sul; Chapecó, Santa Catarina, Brasil; mrclopertusati@ hotmail.com. Trabalho apresentado no I Seminário Latino-Americano de Estudos em Cultura SEMLACult, Foz do Iguaçu/PR, Brasil, 2017.
} 


\begin{abstract}
The present reflection has the objective to present the relevance of Capoeira as a possibility of a dialogue of knowledge in the contemporary discussions around the decolonial processes, from the recognition of its ancestral, intercultural and intangible patrimonial character, as well as its libertarian identity and resistance. Capoeira has been present in more than 160 countries and in all of the continents since its internationalization in the 60's of the last century. The analysis of Brazilian documents such as the Dossiê de Registro e Salvaguarda da Capoeira como Patrimônio Cultural do Brasil (Dossier of Registration and Safeguard of Capoeira as Cultural Heritage of Brazil) and the Estatuto da Igualdade Racial (Statute of Racial Equality) seeks to contribute, firstly, to the strengthening of Capoeira, its knowledge in encounter and its expressions, legitimate cultural assets, that is, for the African identity affirmation of the Brazilian people, but also for each Capoeira practitioner. The dialogical organization of capoeira's knowledge, through the perspectives of its corporeity, musicality, symbology, history and historicity, rituality and ancestry, contributes to the patrimonial care, to the formation of Afro-Brazilian cultural identity.
\end{abstract}

Key words: Capoeira, Identity, Knowledge, Intangible Heritage, Perspectives.

\title{
1. Introdução
}

Enquanto expressão cultural herdada do processo escravocrata Colonial brasileiro, tendo sofrido perseguição, proibição e criminalização pelo Estado na Primeira República, a Capoeira se constituiu em meio a um conjunto de práticas sociais de resistência (SOARES, 2002), na afirmação da identidade afro-brasileira e, nesse processo, contribuindo para o fortalecimento de saberes e expressões culturais populares e ancestrais, inclusive reconhecidas nacional e internacionalmente como Patrimônio Cultural Imaterial brasileiro.

A partir da expansão de sua prática e de seus símbolos em espaços diversificados, por diferentes sujeitos, de classes sociais e nacionalidades diversas, também migrando para todos os cantos do território brasileiro e imigrando para muitos países, a Capoeira tem contribuído para transformações culturais; principalmente a partir de seu processo de internacionalização na década de 60 do século XX (LIMA, 2016; SOARES, 2002), ela tem subvertido códigos eurocêntricos ditos legítimos, a partir de saberes de mestres de Capoeira, vividos e transmitidos por meio de seu ofício popular e ancestral, na Roda de Capoeira e nos mais diferentes espaços sociais.

Seja como luta de resistência dos povos africanos em busca da liberdade, considerando-se que foi historicamente produzida uma visão discriminatória acerca das expressões culturais negras no Brasil, com destaque para o século XIX, seja como uma brincadeira de homens trabalhadores dos portos marítimos em sua hora de folga (negros africanos, mestiços, marujos portugueses e ingleses), é fundamental o estudo e o debate contemporâneo acerca da (s) identidade (s) da Capoeira, de caráter originariamente multidimensional. 
RELACult - Revista Latino-Americana de Estudos em Cultura e Sociedade

Revista Latinoamericana de Estudios en Cultura y Sociedad | Latin American Journal of Studies in Culture and Society V. 03, ed. especial, dez., 2017, artigo no 518 | relacult.claec.org | e-ISSN: 2525-7870

\title{
2. Cuidado Patrimonial da Capoeira por meio da valorização da (s) identidade (s) afro- brasileira (s)
}

Conceber a Capoeira, na sua multidimensionalidade, não é tarefa fácil, é preciso estar disposto a aceitar sua complexidade cultural como uma de suas características, bem como a sua dinâmica transformadora.

Proporcionando a seus praticantes a oportunidade de um diálogo de saberes no âmbito da roda de jogo, este espaço de realização cultural se configura como uma unidade da diversidade, onde processos de decoloniais são potencializados. A Capoeira assim pode ser dinamizada em vista do reconhecimento de saberes afro-brasileiros de profundo significado ancestral, pelo que se integram culturas, identidades individuais e coletivas, em seu aspecto intercultural, patrimonial, enquanto herança cultural imaterial.

Buscando refletir acerca do que é patrimônio, do que é patrimônio cultural e sobre patrimônio cultural imaterial, é imprescindível considerar a Constituição Federal (CF) brasileira de 1988, nos seus artigos 215 e 216 (BRASIL, 2016, p.126-127).

Patrimônio vem a ser, então, todo tipo de bem que caracteriza um determinado povo ou a humanidade. Pela CF ficou estabelecido que o patrimônio cultural brasileiro é composto de bens de natureza material e imaterial, incluídos aí os modos de criar, fazer e viver dos grupos formadores da sociedade brasileira, considerados aqui indígenas, africanos e europeus. De forma característica, a Capoeira está inclusiva na categoria de patrimônio imaterial.

Segundo o Instituto do Patrimônio Histórico e Artístico Nacional (IPHAN, 2017a), autarquia do Ministério da Cultura:

\begin{abstract}
Os bens culturais de natureza imaterial dizem respeito àquelas práticas e domínios da vida social que se manifestam em saberes, ofícios e modos de fazer; celebrações; formas de expressão cênicas, plásticas, musicais ou lúdicas e nos lugares, tais como mercados, feiras e santuários que abrigam práticas culturais coletivas. Essa definição está em consonância com a Convenção da Unesco para a Salvaguarda do Patrimônio Cultural Imaterial, ratificada pelo Brasil em $1^{\circ}$ de março de 2006, que define como patrimônio imaterial "as práticas, representações, expressões, conhecimentos e técnicas - junto com os instrumentos, objetos, artefatos e lugares culturais que lhes são associados - que as comunidades, os grupos e, em alguns casos, os indivíduos reconhecem como parte integrante de seu patrimônio cultural".
\end{abstract}

Reconhecida como patrimônio cultural imaterial do Brasil pelo IPHAN, conforme processo $n^{\circ}$ 01450.02863/2006-80 - com Registro em 21/10/2008, a Capoeira reúne em si 'saberes' e 'expressões' da vida, por meio das categorias 'saber' e 'formas de expressão', respectivamente se referindo ao 'Ofício dos Mestres de Capoeira' e à 'Roda de Capoeira', 
pelos quais são dinamizados diálogos entre corporeidades, historicidades e ancestralidades dos capoeiristas, respeitando-se uma musicalidade e uma ritualidade comum.

\subsection{Ofício dos Mestres de Capoeira - Multidimensionalidade de Saberes}

$\mathrm{Na}$ descrição acerca do 'Ofício dos Mestres de Capoeira' encontrada no site do IPHAN (2017b, p.2), como bem cultural registrado, o exercício deste bem é reconhecido e atribuído àqueles sujeitos detentores dos conhecimentos tradicionais desta manifestação e responsáveis pela transmissão oral das suas práticas, rituais e herança cultural. Para que a cultura da Capoeira continue presente, ela depende diretamente da cadeia de transmissão dos saberes e fazeres dos mestres a seus aprendizes, bens estes que são transmitidos pela oralidade e pela corporeidade, por meio de inter-relações gestuais, de participações musicais interculturais e da interação física, cognitiva e afetiva nas rodas de jogo de Capoeira, nas ruas, nas academias, em escolas e universidades, dentre outros espaços de convívio social.

Especificamente com relação a proposições e estudos científicos sobre os saberes da capoeira, cuja fonte e fundamentos estão nas pessoas dos mestres, toma-se a temática da XII Clínica de Capoeira como exemplo, que tratou da capoeira como um 'Encontro de Saberes: Unidade na Diversidade'; este evento ocorreu no ano de 2010, na Universidade de São Paulo (USP), organizado pelo Centro de Práticas Esportivas da Universidade de São Paulo (CEPEUSP), a partir do Grupo de Estudos do Centro de Estudos e Pesquisas da Capoeira (CEPECAP) da USP.

O evento Clínica de Capoeira ocorre bianualmente desde 1985, sendo que em 2010 foram debatidas questões em torno de um conjunto de saberes que se encontram na Capoeira e na Roda de Capoeira (espaço-tempo máximo da expressão desses saberes) sob o comando dos mestres, os quais são o patrimônio vivo da cultura e da identidade afro-brasileira, assim como outros mestres da cultura popular que detêm saber ancestral.

Concebidos numa inter-relação, em encontro, ao modo de um diálogo transcultural e intercultural, como uma unidade na diversidade, a Capoeira representa, por meio de sua Roda de prática de jogo, esta unidade de saberes. Esses saberes constituem dinamicamente um todo social ou uma totalidade de experiências que podem ser vivenciadas na Roda de Capoeira, ligados a conhecimentos de cunho antropológico, filosófico, teológico, psicológico, histórico, sociológico e empírico da Capoeira.

Além de se tematizar a Capoeira como espaço-tempo de diálogo de saberes, ou de saberes em diálogo, outro aspecto importante para a compreensão de sua estrutura multidimensional são concepções apresentadas por documentos oficiais nos contextos de educação, cultura, esporte e lazer, nos quais atuam os profissionais docentes em capoeira, por 
meio de seu ofício de ensinar a capoeira, principalmente em se tratando do 'Dossiê de Registro e Salvaguarda da Capoeira como Patrimônio Cultural do Brasil' e do 'Estatuto da Igualdade Racial'.

Nos estudos do congresso da XII Clínica de Capoeira da USP (CEPEUSP, 2010) foram caracterizados os seguintes saberes da Capoeira: saber ancestral; saber presente; saber intuitivo; saber espiritual; saber cultural; saber histórico; saber humano; e saber popular.

A seguir é possível ver na Figura 1 uma ideia da dinâmica que envolve estes saberes em diálogo, vivenciados em sua forma mais forte quando dos jogos de Capoeira na Roda, por meio dos ensinamentos dos mestres e da participação de cada aprendiz capoeirista:

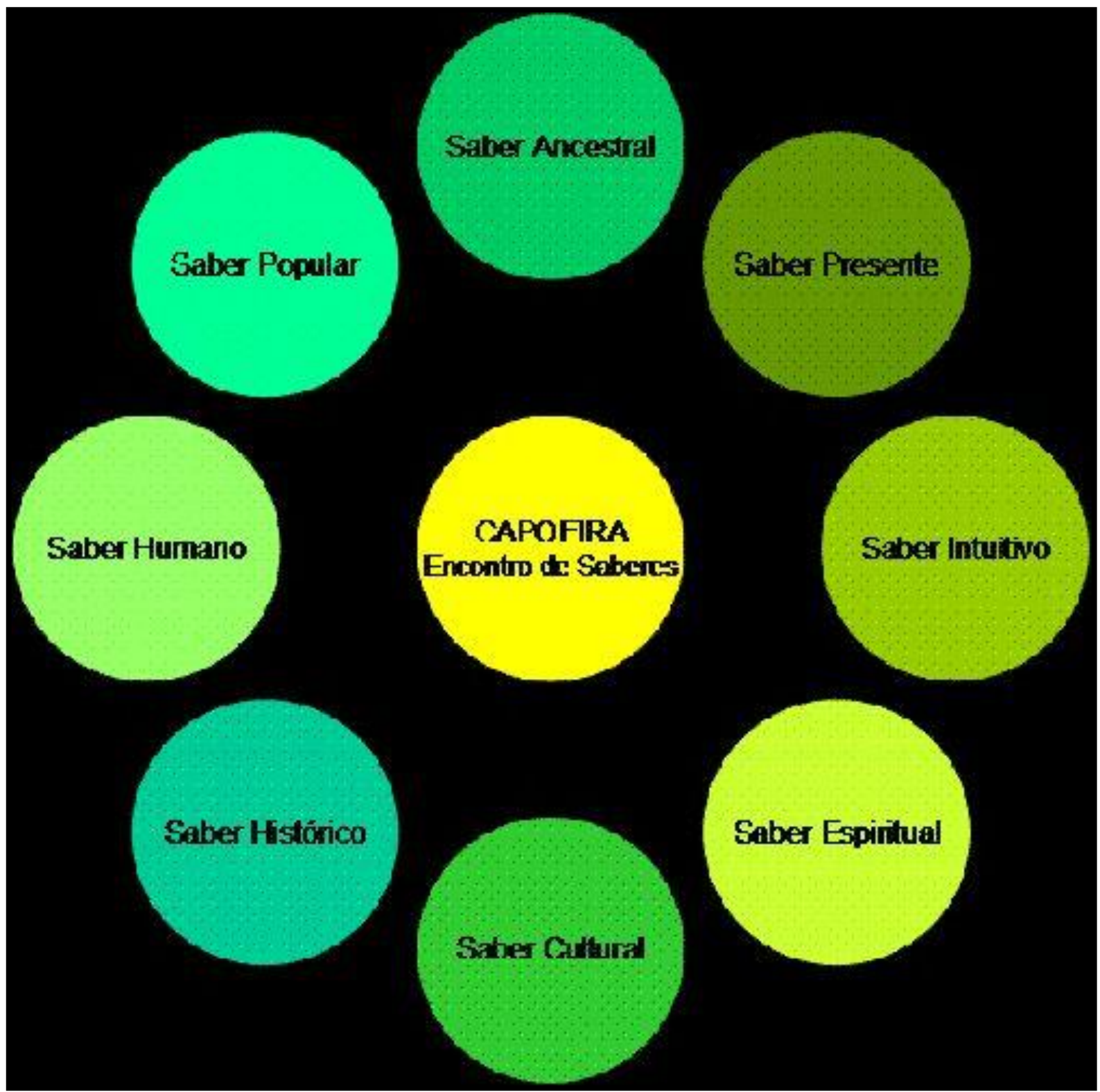

Figura 1 - Encontro de Saberes: Unidade na Diversidade.

Fonte: CEPEUSP. Clínica de Capoeira. 2010. 
Esses elementos merecem estudos mais aprofundados em momento oportuno; apresentá-los, mesmo que ligeiramente, em suas denominações, tem o objetivo de que se tenha mais próxima a noção da multidimensionalidade epistemológica da Capoeira.

\subsection{Roda de Capoeira - Formas de Expressão}

No que diz respeito à 'Roda de Capoeira', trata-se de um elemento estruturante da Capoeira como manifestação cultural.

Profundamente ritualizada, a roda de capoeira congrega cantigas e movimentos que expressam uma visão de mundo, uma hierarquia e um código de ética que são compartilhados pelo grupo. Na roda de capoeira se batizam os iniciantes, se formam e se consagram os grandes mestres, se transmitem e se reiteram práticas e valores afro-brasileiros. (IPHAN, 2017c, p.1).

Expressão cultural que se apresenta por meio de uma roda, de um círculo de pessoas reunidas em torno de um mesmo objetivo de se sentir livre, capaz de reunir canto, toques de instrumentos musicais (berimbaus, atabaque, pandeiro, agogô e reco-reco), dança, golpes marciais, jogo, brincadeira, símbolos e rituais de herança africana, a Capoeira organizada como Roda é espaço e tempo de realização e afirmação da identidade afro-brasileira.

Por sua dinâmica intercultural de reunir pessoas de diferentes pensamentos, expressões étnico-raciais e artístico-culturais, a Roda de Capoeira foi reconhecida como Patrimônio Cultural Imaterial da Humanidade pela UNESCO, por ocasião da $9^{a}$ Sessão do Comitê Intergovernamental para a Salvaguarda, em novembro de 2014, em Paris.

\subsection{Internacionalização da Capoeira, globalização e identidade (s) afro-brasileira (s)}

Em vista de sua multidimensionalidade cultural, a Capoeira é a expressão dos mais diferentes sincretismos brasileiros, herança constituída em meio aos sofrimentos dos povos da diáspora africana, arte-luta percebida em cada capoeirista que expressa sua corporeidade, com feições do sujeito diaspórico negro africano que foi escravizado, porém, que lutou e resistiu, bem como que tem valor inestimável em cada mestre, por seu ofício, um patrimônio vivo da nação brasileira, cada qual herdeiro de um legado sui generis.

Faz parte do processo de constituição histórico-cultural da Capoeira a passagem de sua prática nas ruas - na marginalidade, para sua prática controlada em local fechado a partir da década de 30, passando por sua expansão mais sistematizada na década de 50 para Rio de Janeiro e São Paulo, pela sua internacionalização (Estados Unidos e Europa) nas décadas de 60 e 70, concomitantemente à sua expansão em todo o território nacional, sul do país, América Latina, Ásia e África, com maior ênfase nos anos 80 e 90. 
Esse processo de internacionalização da capoeira a partir das décadas de 60 e 70 condiz com a abertura do país ao capital estrangeiro, muita coisa se tornou cultura de folclore para turista, principalmente em capitais como Salvador, Recife e Rio de Janeiro.

Vários mestres de capoeira da Bahia, do Rio de Janeiro e de São Paulo vão para o exterior nesta época, em meio ao processo de globalização que exige novas posições-deidentidade (fortalecimento de identidades locais ou produção de novas identidades); refletindo acerca da dialética das identidades, concordando com Hall (2006, p.84), significa que a globalização faz contestar e deslocar identidades centradas, "fechadas", de uma cultura nacional (Idem, p.87), tal como a da Capoeira.

Para refletir esta dialética de identidades, ao mesmo tempo em que a Capoeira continua se desenvolvendo mundo afora, juntamente dela a Língua Portuguesa se expande:

\footnotetext{
Nas Américas, no Japão, na China, em Israel, na Coréia, na Austrália, na África e em praticamente toda a Europa. A capoeira disseminou-se pelo mundo com entusiasmo. Mesmo sem falar português, um chinês, um árabe, um judeu ou um americano podem repetir o compasso da mesma música, a arte do mesmo passo e a ginga do mesmo toque. (IPHAN, 2007, p.91 apud GIL, 2004).
}

A intervenção no mundo realizada pelos capoeiristas ocorre por meio das práticas e saberes transmitidos ancestralmente, configurados no que se chama de 'ancestralidade', cujo caminho de comunicação é vibrante e “(...) envolve seus personagens num campo fértil de produção de saberes, e que explica os fenômenos existentes (...)" (ABIB, 2004). A cultura brasileira da Capoeira, em sua identidade afro-brasileira de resistência, libertação e ludicidade ancestral, instaura e promove diferentes movimentos de transformação social onde ela é praticada.

Enraizado no cotidiano das comunidades e vinculado ao seu território e às suas condições materiais de existência, um patrimônio imaterial como a Capoeira é transmitido de geração em geração e constantemente recriado e apropriado por indivíduos e grupos sociais como importantes elementos de sua própria identidade (IPHAN, 2012a).

\subsection{Registro da Capoeira como Patrimônio Cultural do Brasil e Estatuto da Igualdade Racial: política de valorização do patrimônio imaterial}

Em análise sobre o Capítulo II do Estatuto da Igualdade Racial (EIR), também é possível perceber várias dimensões relativas à Capoeira, não diretamente aos seus saberes em unidade (CEPEUSP, 2010), ou às definições apresentadas pelo dossiê do IPHAN (2003; 2017b, p.2; 2017c, p.1) que abordam acerca do Ofício dos Mestres de Capoeira (Saber) e da 
Roda de Capoeira (Forma de Expressão), mas sim com destaque para os conceitos de ‘educação, cultura, esporte e lazer' que intitulam este Capítulo II.

Com atenção ao caráter educativo-formativo da capoeira nas escolas e universidades, contextualizada no ensino e estudo da história geral da África e da história da população negra no Brasil (BRASIL, 2010, Art. 11, p.04), fica evidente uma possibilidade de ruptura com processos hegemônicos coloniais eurocêntricos de ensino apenas daquela história contada por uma elite branca, patriarcal e exploradora. De acordo com o que está disposto no parágrafo primeiro, "Os conteúdos referentes à história da população negra no Brasil serão ministrados no âmbito de todo o currículo escolar (...)" (BRASIL, 2003), abrindo espaço para a capoeira e seus saberes quando é acrescido o objetivo de resgatar a contribuição decisiva desses conteúdos "para o desenvolvimento social, econômico, político e cultural do País".

Em complementação, o Art. 13, na mesma Seção II do EIR, atribui que "O Poder Executivo Federal, por meio dos órgãos competentes, incentivará as instituições de ensino superior públicas e privadas, sem prejuízo da legislação em vigor, a (inciso II): “incorporar nas matrizes curriculares dos cursos de formação de professores temas que incluam valores concernentes à pluralidade étnica e cultural da sociedade brasileira"; ademais, do Art. 17 a 20 do EIR, acerca da capoeira como cultura, esporte e lazer, fica mais evidenciado que é urgente o compromisso do Poder Público em assegurar a valorização da Capoeira como patrimônio imaterial, ou seja, o Ofício dos Mestres, permitindo a mestres e educadores em capoeira, a capoeiristas e demais pesquisadores, ampliarem sua busca por recursos na efetivação de ações de afirmação da (s) identidade (s) afro-brasileiras.

Por fim, esses aspectos de saberes em encontro (CEPEUSP, 2010), além da concepção do EIR (BRASIL, 2010) abrangendo a Capoeira como direito à educação, à cultura, ao esporte e ao lazer, em ambos os casos se tem uma multidimensionalidade de conceitos e práticas que estão no início de sua apreensão pela comunidade capoeirística neste mundo globalizado em curso, em meio a uma transnacionalização das práticas afro-brasileiras que possa contribuir para a valorização da Capoeira como patrimônio imaterial, sem descaracterizá-la, portanto, nos aspectos ancestrais, presentes, intuitivos, espirituais, culturais, históricos, humanos e populares dos saberes dos mestres, nas Rodas de Capoeira.

\section{Conclusões}

A Capoeira, enquanto patrimônio cultural imaterial brasileiro reconhecido internacionalmente, por meio de seu conjunto de saberes em diálogo constante, pode e deve ser espaço e tempo para se buscar uma compreensão complexa do dinâmico mundo social 
contemporâneo, frente a formas de expressão coloniais, eurocêntricas e hegemônicas de poder que influenciam na formação da (s) identidade (s) do (s) sujeito (s), mormente por meio das mídias que são formadoras de opinião.

Considerando-se que no seu processo de internacionalização a Capoeira passou a receber grandes influências do processo de globalização, no tocante aos elementos do mercado e ao capitalismo, quando saiu do Brasil para o mundo, a partir da década de 60 no século XX, é preciso apresentar positivamente o fato de que ela também influenciou, e tem influenciado, outras pessoas, outros coletivos, outras nações pelo processo de mundialização de saberes, fazeres, conhecimentos, símbolos, práticas e vivências que ela encerra.

Nesse sentido, a Capoeira se constitui como um complexo intercultural, pelo qual novas perspectivas e/ou possibilidades de debates pós-coloniais podem ser conduzidos em vista de fortalecer a (s) identidade (s) afro-brasileira (s), salvaguardados os saberes do Ofício dos Mestres e potencializadas as suas formas de expressão na Roda de Capoeira, com atenção à atuação dos meios de comunicação e seu relevante papel de difusão cultural.

Para que a Capoeira, compreendida como um conjunto de saberes em encontro, em diálogo, como uma unidade na diversidade, torne-se uma proposta contra-hegemônica, é mister que em seus conteúdos temáticos e em seus contextos sempre se tenha em mente a urgência de mobilização de processos de alteridade e solidariedade.

Buscando responder que tipos de novas perspectivas de construção de formas de pertencimento podem ser possíveis de existir como resistência aos discursos hegemônicos, portanto, eis que no âmbito da (s) cultura (s) e da (s) identidade (s) afro-brasileira (s) se tem os saberes e as formas de expressão da Capoeira como possibilidades de promoção de dialogicidades, de inter-relações, da interculturalidade e do patrimônio imaterial.

No sentido de procurar superar sentimentos de minimização cultural por conta da memória de colonização, disciplina e escravização de mentes/espíritos/corpos, desde o século XVI, a Capoeira e outras formas de expressão e linguagem cultural, como as artes, a música, a dança, a literatura dentre outras podem ser, conjuntamente da pesquisa científica, elementos para construção de uma nova história de Nuestra America; na reconstrução de direitos; na articulação de políticas de igualdade e de identidade; na construção intercultural da igualdade e da diferença; pontos cruciais da reflexão de Santos (2010), que inspiram pensar também, então, os saberes ancestrais da capoeira (pluralidade externa) dialogando com os saberes da Ciência (pluralidade interna das práticas científicas), numa ecologia de saberes com participação de diferentes saberes e seus sujeitos, valha dizer, mestres de Capoeira em seu 
ofício, aprendizes, familiares, pesquisadores, educadores físicos, historiadores, artistas, artesãos, músicos e tantos outros sujeitos.

Frente a questões e tendências mundiais antidemocráticas, fundamentar as interrelações epistemológicas da Capoeira, ou os seus diálogos de saberes, no âmbito de uma educação intercultural já nas escolas seria uma forma interessante de fortalecê-la como patrimônio, bem como colaboraria muito na educação escolar em uma ecologia de conhecimentos escolares, em vista de uma nova cultura política curricular, sem que se perca a criatividade e a sensibilidade, no trato contínuo de questões étnico-raciais.

Por fim, além de seu caráter intrínseco e identitário de resistência e alegria, bem como da dinâmica plural de saberes em encontro, há o aparato legal por meio do Estatuto da Igualdade Racial (BRASIL, Lei 12.288/2010) e das Leis complementares LDBEN 9394/96 que tratam do ensino do conteúdo de História africana, afro-brasileira e indígena (Idem, Leis $n^{\circ} 10.693 / 2003$ e n 11.645/2008), dão legitimidade às práticas da Capoeira como educação, cultura, esporte e lazer; sobre esses temas há bastante pesquisa produzida nos bancos de dados científicos, sendo o desafio agora aproximar e socializar esses conhecimentos da academia por meio de linguagem acessível a todos e todas que queiram conhecer mais sobre a Capoeira e suas manifestações.

\section{Referências}

ABIB, Pedro Rodolpho Jungers. Capoeira Angola: cultura popular e o jogo dos saberes na roda. 2004. 173 f. Tese de Doutorado (Doutorado em Ciências Sociais Aplicadas à Educação)-Faculdade de Educação, Universidade Estadual de Campinas (SP), Campinas, 2004. Disponível em:

https://periodicos.sbu.unicamp.br/ojs/index.php/resgate/article/view/8645622. Acesso em: 02 mai. 2017. (Tese).

BRASIL. Constituição da República Federativa do Brasil: texto constitucional promulgado em 5 de outubro de 1988, com as alterações determinadas pelas Emendas Constitucionais de Revisão ${ }^{\text {os }} 1$ a 6/94, pelas Emendas Constitucionais n ${ }^{\text {os }} 1 / 92$ a 91/2016 e pelo Decreto Legislativo no 186/2008. Brasília: Senado Federal, Coordenação de Edições Técnicas. 2016. 496 p. Disponível em: https://www2.senado.leg.br/bdsf/bitstream/handle/id/518231/CF88_Livro_EC91_2016.pdf?se quence $=1$ ? concurso=CFS\%202\%202018. Acesso em: 02 mai. 2017. (Legislação Completa)

LDB $n .{ }^{\circ}$ 9.394/1996; Lei $n .{ }^{\circ}$ 10.693/2003; Lei $n .{ }^{\circ}$ 11.645/2008. Disponível em: http://www.planalto.gov.br. Acesso em: 10 junho. 2017. (Legislação)

. Lei $n^{o} 12.288$, de 20 de Julho de 2010 - Estatuto da Igualdade Racial. Brasília: Planalto, 2010c. Disponível em: www.planalto.gov.br/ccivil_03/_Ato20072010/2010/Lei/L12288. Acesso em: 09 mai. 2017. (Legislação) 
CEPEUSP. XII Clínica de Capoeira - Saberes em encontro: unidade na diversidade. Imagem com Descrição. São Paulo. 2010. Disponível em:

http://clinicadecapoeira2010.wordpress.com/. Acesso em: 15 jun. 2017. (Site do Congresso)

GIL, Gilberto. Brasil, paz no mundo. Genebra (Suíça): Ministério da Cultura/ONU, 2004. Vídeos. Disponível em: www.youtube.com/watch?v=C69hZYNhuv0 e www.youtube.com/watch?v=PE6zcYZDOiE. Acesso em: 18 mar. 2017. (Vídeos do YouTube)

HALL, Stuart. A identidade cultural da pós-modernidade. 10. ed. Rio de Janeiro: DP\&A, 2006. (Obra Completa)

INSTITUTO DO PATRIMÔNIO HISTÓRICO E ARTÍSTICO NACIONAL. Dossiê: Inventário para Registro e Salvaguarda da Capoeira como Patrimônio Cultural do Brasil. Brasília: IPHAN, 2007. Disponível em:

http://portal.iphan.gov.br/portal/baixaFcdAnexo.do;jsessionid=957F9223953BDCCB0F4F37 F5D2EC3254?id=1388. Acesso em: 09 mar. 2017. (Obra Completa em meio digital)

Patrimonial - O que é Patrimônio Imaterial? IPHAN: 2017a. Disponível em: Informação http://portal.iphan.gov.br/bcrE/pages/conPatrimonioE.jsf?tipoInformacao=1. Acesso em: 09 mai. 2017. (Acervo Digital)

. Bens

Registrados - Categoria (Consulta por) - Formas de Expressão - Ofício dos Mestres de Capoeira. Parecer 031/08. IPHAN: 2017b. Disponível em:

http://portal.iphan.gov.br/bcrE/pages/folBemCulturalRegistradoE.jsf e http://portal.iphan.gov.br/pagina/detalhes/67. Acesso em: 09 mai. 2017. (Acervo Digital) Bens

Registrados - Categoria (Consulta por) - Formas de Expressão - Roda de Capoeira. Parecer 031/08. IPHAN: 2017c . p.1. Disponível em:

http://portal.iphan.gov.br/bcrE/pages/folBemCulturalRegistradoE.jsf e http://portal.iphan.gov.br/pagina/detalhes/66. Acesso em: 09 mai. 2017. (Acervo Digital)

LIMA, Lucia Correia. Mandinga em Manhattan: internacionalização da Capoeira. Rio de Janeiro: MC\&G, 2016. 207p. (Obra Completa)

SANTOS, Boaventura de Sousa. A gramática do tempo: para uma nova cultura política. 3. ed. São Paulo: Cortez, 2010. (Coleção para um novo senso comum; v. 4). (Obra Completa)

SOARES, Carlos Eugênio Líbano. A capoeira escrava e outras tradições rebeldes no Rio de Janeiro (1808-1850). $2^{\mathrm{a}}$ ed., revisada e ampliada. Campinas: UNICAMP, Centro de Pesquisa em História Social da Cultura, 2002. (Obra Completa) 